\title{
> A concepção relacional do poder em Foucault e a omissão da valoração ética
}

\author{
$>$ The relational conception of power on Foucault \\ and the omission of ethical valoration
}

\begin{abstract}
por Igor Corrêa de Barros
Graduando em Filosofia pela Universidade Federal de São João del Rei. Bolsista da Capes pelo programa Residência Pedagógica. Formado em Técnico em Informática pelo Instituto Federal de Educação, Ciência e Tecnologia do Sudeste de Minas Gerais, Campus Rio Pomba. E-mail: igor.cbarros21@gmail.com. ORCID: 0000-0003-1386-955X.
\end{abstract}

\begin{abstract}
Resumo
O presente artigo tem por objetivo apresentar alguns dos elementos centrais da analítica do poder proposta por Michel Foucault. Após situar e caracterizar a noção foucaultiana de poder a partir dos escritos genealógicos, examina-se como a concepção relacional de poder orienta as investigações acerca da emergência e estruturação do poder disciplinar. Por fim, recuperamos a crítica de Andrew Sayer à noção foucaultiana de poder, segundo a qual falta à concepção foucaultiana uma elaboração explícita do componente valorativo e normativo do poder. Ao final, considera-se a pertinência dos pontos levantados por Sayer.
\end{abstract}

Palavras-chave: Foucault. Poder. Disciplina. Andrew Sayer.

\begin{abstract}
This article aims to present some core elements of the analytic of power by Michel Foucault. After locating and characterizing the foucaultian conception of power, based on his genealogical works, we consider how his relational conception guides the investigations concerning the emergence and the organization of the disciplinary power. In the last section, we recover the Andrew Sayer's criticism to the foucaultian conception of power according to which the lack of an explicit consideration of the normative and evaluative component of the power is a crucial point. Lastly, we consider the relevant of the points mentioned by Sayer.
\end{abstract}

Keywords: Foucault. Power. Discipline. Andrew Sayer. 


\section{Considerações iniciais}

Foucault é conhecido principalmente por suas pesquisas envolvendo os temas da loucura, da punição, dos hospitais psiquiátricos, da prisão, da sexualidade, da epistemologia das ciências humanas, entre outros. Contudo, suas pesquisas ao longo dos anos 1970 sobre a questão do poder ocupam lugar de destaque na sua produção. A sua concepção de poder, criticando aspectos fundamentais da tradição filosófica ocidental, acaba por oferecer uma nova forma de interpretação dos fenômenos sociais e políticos; e, por isso, talvez seja considerado o aspecto mais influente e original do seu pensamento.

É possível organizar as abordagens que guiam a produção de Foucault em torno de três tipos de investigações históricas, que são normalmente tomadas como fases distintas da sua produção: a arqueologia, a genealogia e uma última fase que poderíamos chamar ética/estética. Como nos lembram Rabinow e Dreyfus, tal classificação é em certo sentido supérflua, no entanto esse é um modo de lidar com as frequentes mudanças de interesses de pesquisa e de elaboração e combinação de abordagens metodológicas propostas por Foucault. ${ }^{1}$ Isso significa, e nos serve de alerta, que também as noções ou conceitos que orientaram e em torno dos quais se estruturaram as suas investigações também mudaram ao longo do tempo.

Os trabalhos associados à primeira fase, a fase arqueológica, são principalmente O nascimento da clínica (1963), As palavras e as coisas (1966) e A arqueologia do saber (1969). Nessa fase, Foucault estava interessado em examinar as regras de formação e os regimes de verdade das disciplinas; sobretudo, aquelas por meio das quais os seres humanos tentam compreender a si mesmos, isto é, a medicina e as ciências humanas em geral.

\footnotetext{
${ }^{1}$ Cf. Hubert Dreyfus e Paul Rabinow, Michel Foucault: uma trajetória filosófica. Para além do estruturalismo e da hermenêtica, 1995, p. 116; e Cf. Amy Allen, The anti-subjective hypothesis: Michel Foucault and the death of the subject, 2000.
} 
Os trabalhos associados à segunda fase, a fase genealógica, são, principalmente, Vigiar e punir (1975) e a Histórica da sexualidade, volume 1: A vontade de saber (1976). É mais precisamente nessa fase que Foucault se volta para a compreensão de como a própria produção do conhecimento é regida por todo um sistema complexo de práticas, e não apenas de práticas discursivas. Foucault está especialmente interessado em entender como a genealogia das formas de exercício de poder e de produção de saber articulam-se para produzir verdades.

A partir do final da década de 1970, Foucault dedica-se a temas associados à ética e à estética. Os trabalhos representativos dessa fase são principalmente os volumes 2 e 3 da História da sexualidade: Os usos do prazer (1984) e O cuidado de si (1984). Nessa fase, Foucault explora a ideia de um sujeito ético ativo, bem como, o ideal de tornar a própria vida uma obra de arte; para alguns intérpretes, um interesse pelo tema da estética da existência.

Neste artigo, nos ocuparemos de alguns dos elementos centrais da concepção de poder proposta por Foucault, principalmente a partir das obras Vigiar e punir (1975) e A vontade de saber, lançado em 1976. Trata-se de um esforço em identificar quais são os elementos principais indicados por Foucault; tal tarefa é bastante complexa uma vez que o pensador francês nunca escreveu de modo sistemático uma obra dedicada especificamente ao tema do poder, tampouco tinha a pretensão de elaborar uma teoria acerca do poder. Por outro lado, Foucault nunca afastou os seus holofotes da temática complexa do poder. É, então, no mapeamento das considerações de Foucault e na reconstrução das articulações entre os elementos indicados que podemos ter uma visão geral da sua concepção de poder.

Nesse mapeamento, podemos notar que foi para compreender a relação entre saber e poder que Foucault passou a enfatizar, nos anos 1970, o componente genealógico da sua metodologia de investigação histórica. E é a partir dessa mudança de ênfase que emerge como central nas suas investigações o tema do poder e das relações de poder. Particularmente em Vigiar e punir, Foucault está 
interessado como se formam e se articulam na sociedade industrial múltiplos mecanismos e dispositivos de controle geral e de vigilância sobre os indivíduos. Daí o interesse de Foucault no funcionamento de instituições como hospitais psiquiátricos, prisões, escolas e fábricas.

Na seção a seguir, em contraste com as noções substanciais de poder criticadas por Foucault, apresentamos a sua noção relacional e a relevância dos aspectos periféricos do poder. Na terceira seção, exploramos como essa concepção geral aparece na análise que Foucault oferece para a emergência e para um modo específico de operação do poder, e dos saberes associados, nas sociedades modernas: o poder sobre os corpos na sua forma disciplinar. A fim de destacar a pertinência e atualidade da concepção de poder de Foucault, apresentamos na quarta seção o esforço de Andrew Sayer em desenvolver e superar as limitações da proposta foucaultiana.

\section{Microfísica do poder: protagonismo dos poderes periféricos}

Antes de entender o poder em Foucault, é preciso ter conhecimento das formas tradicionais de análise de poder que o autor em questão contesta. Não se trata de refutar as teorias políticas realizadas anteriormente, mas de entender, por um percurso histórico e por uma investigação empírica, como o homem ocidental chegou ao que é hoje, e, no caso da política, entender como o poder acontece e contribui para a constituição da subjetividade desse sujeito.

Quanto ao primeiro aspecto, de fato, a emergência da analítica do poder em Foucault pode ser entendida como o resultado de uma mudança de ênfase na articulação de dois procedimentos de investigação histórica, o movimento da arqueologia para a genealogia. Ao dar ênfase à genealogia, Foucault pretendia não apenas compreender as regras que governam o discurso científico acerca dos assuntos humanos. Nos termos do próprio Foucault, a genealogia lança um olhar "para as continuidades das práticas culturais que a arqueologia isola"; 
especificamente, para as práticas e as relações entre poder, saber e os corpos dos indivíduos na sociedade moderna. De modo que: "a genealogia de Foucault foi o maior passo em direção a uma complexa análise do poder"2.

A contribuição decisiva da genealogia para a analítica do poder desenvolvida por Foucault pode ser captada pela máxima do genealogista: na formulação de Dreyfus e Rabinow, examinando em detalhe a superfície de supostas continuidades e progressos, ele identifica e revela descontinuidades e recorrências e mostra que ali "onde se supunha profundidade, interioridade e finalidade", na realidade, "não há nenhuma essência"3. Foucault está interessado então em investigar "como a objetividade científica e as intenções subjetivas emergem, juntas, num espaço estabelecido não por indivíduos, mas por práticas sociais"4. Sujeitos e objetos emergem em certos campos nos quais as práticas operam; eles não preexistem, eles mesmos são produtos de manobras sociais. Isso significa que não há entidades substanciais cujas essências se conectam de determinado modo com outras entidades substanciais. Isso sugere que o poder tem uma natureza completamente relacional. A relação de poder é aquela a partir da qual emerge um campo estrutural de conflitos. É na identificação de certos rituais meticulosos de poder que se pode localizar e especificar a forma como o poder funciona, o que ele efetivamente faz e como faz. ${ }^{5}$ A relevância desse aspecto relacional é adequadamente notada no contraste com o caráter substancial das concepções tradicionais de poder e que se encontra igualmente implicado nas análises das relações de poder.

Para Foucault, não se trata de refutar as teorias políticas tradicionais, mas de entender, por um percurso histórico e por uma investigação empírica, como o homem ocidental chegou ao que é hoje, e, no caso da política, de entender como o poder acontece e contribui para a constituição da subjetividade dos sujeitos. Para

\footnotetext{
${ }^{2}$ Hubert L. Dreyfus; Paul Rabinow, Michel Foucault: uma trajetória filosófica. Para além do estruturalismo e da hermenêutica, 1995, p. 117.

${ }^{3}$ Ibidem, p. 119.

${ }^{4}$ Ibidem, p. 121.

${ }^{5}$ Ibidem, p. 122.
} 
tanto, Foucault distinguiu sua analítica do poder daquelas concepções que prevaleciam na tradição do pensamento político e filosófico: o poder como mecanismos que tem por objetivo promover a sobrevivência do Estado e das instituições; de um lado a noção de um poder jurídico pautado nas normas e leis para o bem estar e regulação da sociedade; e de outro a noção do poder como dominação, que tem por objetivo o controle de um grupo sobre o outro, ou seja, opressão de classe e manutenção de privilégios, como entendida pela perspectiva marxista.

As concepções políticas que vigoravam na época de Foucault, e que ainda hoje são muito influentes nos estudos sobre política, são marcadas por algumas características. Em geral, entende-se que o poder se manifesta por meio da lei, da coibição; trata-se, portanto, de um modelo de poder essencialmente jurídico. Esse poder compreendido e analisado de modo juridicista acontece sempre por meio da repressão, como uma violência legalizada pelo Estado, é frequentemente exercido na forma de dualismos, como o legal e o ilegal, o oprimido e o opressor. Outra característica comum dessas concepções tradicionais de poder é que o poder é tido como um exercício que acontece de forma universal e uniforme. Esse poder substancial, um poder coisa, é entendido como algo que pode ser acumulado, que provêm de uma fonte, do que se pode apossar, que pode ser concentrado, repartido ou distribuído. É nesse sentido que mesmo com as diferenças existentes entre as variantes, a tradição político-filosófica criticada por Foucault tem em comum o fato de analisar o Estado como ponto inicial do poder, como sendo o órgão central de onde todos os outros poderes se originam. Portanto, segundo o autor, as análises dessa tradição acabam por promover uma supervalorização do Estado. Todas essas concepções das variantes dessa tradição sempre procuraram analisar a estrutura estatal como forma unitária de controle de todo poder.

Voltando-se para a política francesa do seu tempo, Foucault chamou a atenção que também ali na sua sociedade as variantes dessa concepção substancial do poder se manifestavam. Enquanto a esquerda marxista colocava 
o poder em termos de Estado, a direita analisava-o de forma jurídica, enquanto constituição. Ambos lados se preocupavam em denunciar o poder do outro: o totalitarismo dos soviéticos versus o abuso de classe praticado pelo capitalismo ocidental. As duas formas apresentam uma ideia de poder que coloca em primeiro plano o aspecto econômico, deixando em segundo plano a inteligibilidade do poder enquanto maquinaria.

Foucault não avaliou as concepções da ciência política desenvolvidas até então como "inúteis", não se trata de negar a importância dos estudos realizados até aquele momento, mas de formular uma analítica do poder que pudesse apontar um novo caminho para se conceber o poder. Para Foucault, as formas tradicionais não davam conta de entender todos os mecanismos do poder, pois ignoravam importantes aspectos relativos à temática. Foucault buscou então análises empíricas que pudessem oferecer uma nova visão sobre como o poder é efetivamente exercido.

Nos termos da teoria jurídica de filósofos contratualistas como o John Locke, a concepção poder contrato assume que o poder é algo de que a população abdica em prol de um bem comum, realizando assim a passagem de um estado de natureza para a sociedade politicamente organizada. Na visão foucaultiana, o poder não é algo que se pode passar a outra pessoa, pois todos exercem poder. Trata-se de entender o poder como uma estratégia e não como uma propriedade.

Em Por uma ontologia do poder, publicado como um adendo à coletânea de textos de Foucault reunida em Microfísica do Poder (1978), Roberto Machado aborda exatamente como Foucault concebia o poder enquanto ações, estratégia. Na leitura de Machado', o poder para Foucault não é caracterizado como algo global, que possui uma natureza ou está centrado nas mãos de poucos ou em uma única estrutura; pelo contrário, o poder é uma prática constituída historicamente:

\footnotetext{
${ }^{6}$ Roberto Machado, Por uma genealogia do poder, 2012, p. 14, In Michel Foucault, Microfísica do poder, 2012.
} 
O importante é que as análises indicaram claramente que os poderes periféricos e moleculares não foram confiscados e absorvidos pelo aparelho de Estado. Não são necessariamente criados pelos Estado, nem, se nasceram fora dele, foram inevitavelmente reduzidos a uma forma ou manifestação do aparelho central7.

Portanto, pode-se dizer que o poder não existe em si, enquanto conceito, o que existe são as práticas de poder que acontecem em todo o corpo social. Desse modo, Foucault abriu um novo horizonte para a filosofia política ao chamar atenção para as formas plurais de poder, que até então eram desconsideradas ou estudadas como sendo apenas uma ramificação do Estado.

Foucault procurou mostrar que o poder também acontece perifericamente, podendo ser independente da atuação do Estado. Portanto, a analítica foucaultiana parte de uma observação ascendente do poder, parte dos micropoderes para chegar até sua relação ou não com o Estado. Trata-se, desse modo, de contrapor-se à ideia de que o Estado é o órgão central e o único ponto de partida de todo o poder. Os micropoderes têm história e tecnologias próprias, podendo ser independentes do Estado. É exatamente nesses termos que se manifesta o que Foucault chamou de a microfísica do poder: pode-se analisar o poder a partir de um nível micro para entender como se formam os macroníveis, como o Estado e as instituições. Essas relações de poder são múltiplas, com características e impactos diferentes, podem acontecer desde relações pessoais e locais, até mesmo em níveis superiores, como em instituições. Os micropoderes não são estáticos, estão sempre em mutação, pois são processos que variam historicamente.

Não há nos micropoderes uma divisão binária, como opressor e oprimido, pois o poder está em toda parte e é exercido por todos. O objetivo de Foucault é identificar e entender justamente o que está para além desse modelo binário tão presente nas teorias políticas. Para o autor, o poder é melhor entendido quando observado a partir da teia de relações presentes na sociedade.

\footnotetext{
${ }^{7}$ Michel Foucault, Microfísica do poder, 2012, p.14.
} 
Em suma, o poder acontece em forma de práticas, são ações, que não possuem um detentor. O poder não é um objeto, uma coisa, mas sim uma relação, da qual nada nem ninguém está isento. Portanto, tudo o que acontece envolve poder, inclusive a própria resistência ao poder acontece no interior do mesmo, pois nada lhe é externo. Em uma passagem de Vigiar e punir, Foucault ilustra bem como sua concepção diverge da juridicista, que privilegia a economia e considera o poder como propriedade:

Ora, o estudo desta microfísica supõe que o poder nela exercido não seja concebido como uma propriedade, mas como uma estratégia, que seus efeitos de dominação não sejam atribuídos a uma 'apropriação', mas a disposições, a manobras, a táticas, a técnicas, a funcionamentos; que se desvende nele antes uma rede de relações sempre tensas, sempre em atividade, do que um privilégio que se pudesse deter; que se seja dado como modelo antes a batalha perpétua do que o contrato que faz uma cessão ou uma conquista que se apodera de um domínio. Temos, em suma, de admitir que esse poder se exerce mais do que se possui, que não é 'privilégio' adquirido ou conservado da classe dominante, mas o efeito de conjunto de suas posições estratégicas - efeito manifestado e às vezes reconduzido pela posição dos que são dominados. ${ }^{8}$

A concepção foucaultiana de poder é criticada por suprimir o indivíduo, como se a relação de poder retirasse a liberdade individual, como exemplificada na introdução do livro Michel Foucault: conceitos fundamentais (2012), escrito pela professora estadunidense Dianna Taylor. A autora aponta como esse ponto é polêmico: "aqueles que entendem a alegação de que os indivíduos são formados por relações de poder como constituindo uma negação da liberdade consideram que sua visão seja sombria"”.

Explorando mais profundamente, as objeções feitas a Foucault parecem desconsiderar dois aspectos fundamentais de sua analítica do poder: o conceito de relações do poder e o papel da resistência. Relações de poder são uma forma de manipular o campo de ação do outro indivíduo, o que só pode acontecer entre indivíduos livres. Sendo assim, relação de poder sempre é uma forma de tentar moldar a ação do outro indivíduo, que justamente por ser livre, pode responder

\footnotetext{
${ }^{8}$ Michel Foucault, Vigiar e punir, 2010, p. 29.

${ }^{9}$ Dianna Taylor, Michel Foucault: conceitos fundamentais, 2018, p. 37.
} 
de várias maneiras. Desse modo, a liberdade é uma das condições para o exercício do poder entre indivíduos.

O segundo aspecto que explicita a liberdade na concepção foucaultiana de poder é o fato de que onde há poder, há resistência. Embora tenha usado pouco a palavra repressão e não considere o poder como totalmente negativo, a resistência é um dos pontos essenciais para o entendimento do poder em Foucault. A resistência atua no interior do poder, pois nada lhe é externo e por meio dela as relações de poder sempre podem ser alteradas. Dessa forma, as relações de poder necessitam tanto da liberdade, quanto da possibilidade de resistência.

A ideia de liberdade não se opõe ao poder, pois o poder não é essencialmente opressor. Foucault não considerava o poder como sendo totalmente negativo. Para ele, o poder não se manteria e não seria aceito se fosse apenas repressivo, se dissesse apenas não. A dominação exercida pela sociedade capitalista não conseguiria sustentar-se somente pela coerção ou pelo uso da violência. O poder, pelo contrário, formula discursos, induz a prazeres e funciona como uma rede de produção de saberes.

A Vontade de Saber, primeiro volume do estudo História da Sexualidade, lançado em 1976, exemplifica bem o aspecto produtivo do poder. Analisando o lugar da sexualidade na sociedade ocidental, o autor relata como foram incentivados discursos a respeito do sexo, também como foram produzidos saberes sobre a sexualidade, em busca de uma verdade sobre o sexo. Foucault aponta para a necessidade de reflexão sobre a positividade do poder como algo produtivo e transformador:

Temos que deixar de descrever sempre os efeitos do poder em termos negativos: 'ele exclui', ele 'reprime', ele 'recalca', ele 'censura', ele 'abstrai', ele 'mascara', ele 'esconde'. Na verdade o poder produz; ele produz realidade; produz campos de objetos e rituais da verdade. $O$ indivíduo e o conhecimento que dele se pode ter se originam nessa produção ${ }^{10}$.

${ }^{10}$ Michel Foucault, História da sexualidade: A vontade de saber, 2009, p. 161. 
O poder é entendido, na maioria das vezes, como algo que massifica, que reprime e exclui o indivíduo. Para Foucault, como explicitado na passagem acima, poder é exatamente o contrário, pois o indivíduo é produto desse poder. $\mathrm{O}$ indivíduo não é suprimido ou anulado pelo poder, mas é antes de tudo um de seus principais efeitos. A individualização não é consequência de todo tipo de poder, mas de um poder disciplinar, que não pertence a uma instituição ou a um aparelho, mas que atravessa todo o corpo social. Seus métodos minuciosos permitem a sujeição do indivíduo por meio do controle dos corpos, pautada em uma relação de utilidadedocilidade.

\section{Disciplina: um poder sobre os corpos}

Em Vigiar e Punir, de 1975, Foucault aborda a passagem na modernidade de uma concepção de poder espetáculo para uma concepção de poder disciplinar e chama a atenção para o significado do aparecimento da preocupação com o governo dos indivíduos. Nessa perspectiva, o Estado e o território são apenas variáveis que precisam ser governadas. Isso inclui o governo das populações e dos seus problemas próprios, tais como: natalidade, mortalidade, proliferação de doenças, abastecimento, entre outras questões. Para alcançar tal finalidade, ao invés de usar apenas a violência e as leis, como era característico do poder soberano, assiste-se a uma diversificação das táticas e dos dispositivos de poder, que se multiplicam e se espalham por todo o corpo social e são manipulados por múltiplos agentes.

Em suma, ao mesmo tempo que o Iluminismo na Idade Moderna consolidou uma mudança nos saberes e no pensamento, instaurou paulatinamente um novo tipo de poder. As mesmas luzes que trouxeram uma ruptura e uma liberdade, também trouxeram a disciplina, que consolidou o sistema em que vivemos hoje. O poder disciplinar é um tipo específico de relação de poder que é exercido no interior das instituições desde o século XIX. Esse tipo de relação de poder acontece em um nível macrossocial e tem o objetivo de modelar o indivíduo de 
acordo com os interesses econômicos do sistema capitalista, ajustando e corrigindo atitudes indesejadas, ao mesmo tempo em que incentiva condutas e comportamentos desejáveis, como paciência, obediência e resiliência.

O que singulariza o poder disciplinar das outras formas de poder é justamente sua ação meticulosa e exaustiva sobre os corpos, em uma ação de utilidade-docilidade. $\mathrm{O}$ acréscimo na utilidade corresponde ao acréscimo na docilidade e vice-versa. As habilidades do corpo são aumentadas, sempre procurando evitar que elas sirvam como forma de resistência. Esse tipo de poder está pautado em três grandes aspectos: no controle do espaço e do tempo e, principalmente, na vigilância dos indivíduos.

A organização do espaço foi introduzida na política e passou a ser utilizada como forma de exercício do poder, na busca por alcançar objetivos políticos e econômicos. O problema do espaço, agora, torna-se um problema geopolítico. São determinados os espaços que as pessoas devem ocupar, como a casa dos trabalhadores, nas cidades operárias, por exemplo. Foucault chama tal acontecimento de história dos espaços ou história do poder, na qual a determinação geográfica e as construções estão ligadas às formas de disciplina e coerção, desde as construções de táticas de habitat, até a arquitetura institucional. As construções passaram a ser pensadas de acordo com objetivos políticos e econômicos, sendo uma forma de vigilância.

Por meio da ordenação dos espaços são criadas formas celulares de individualidades, o que Foucault chamou de arte das ordenações. Essa arte das ordenações está pautada na separação dos indivíduos uns dos outros em espaços celulares, divididos por paredes ou portões, facilitando o controle da vagabundagem e da ociosidade. Desse modo, há o que Foucault chamou de esquadrinhamento dos corpos, que, por meio da ordenação das multidões, evita motins e proporciona maior conhecimento e domínio sobre os indivíduos. A escola, citada várias vezes por Foucault, é mais um exemplo de instituição que procura moldar o comportamento dos indivíduos e formar corpos dóceis e 
produtivos por meio de vários mecanismos disciplinares e normativos. A escola controla o tempo de cada aula e também organiza o espaço onde são colocados cada indivíduo de acordo com sua função. A separação dos alunos por carteiras permite uma melhor visualização de cada aluno, promovendo melhor controle das indisciplinas por meio da ordenação das multiplicidades desordenadas. Foucault enfatiza:

\begin{abstract}
a organização de um espaço serial foi uma das grandes modificações técnicas do ensino elementar. Permitiu ultrapassar o sistema tradicional (um aluno que trabalha alguns minutos com o professor, enquanto fica ocioso e sem vigilância o grupo confuso dos que estão esperando). Determinando lugares individuais, tornou possível o controle de cada um e o trabalho simultâneo de todos. Organizou uma nova economia do tempo de aprendizagem. Fez funcionar o espaço escolar como uma máquina de ensinar, mas também de vigiar, de hierarquizar, de recompensar. ${ }^{11}$
\end{abstract}

Depois de separados os espaços, a formação da individualidade acontece também através do controle do tempo, pois é exigido dos corpos uma rapidez e eficácia na realização das atividades. $\mathrm{O}$ uso de cronogramas e a separação das atividades busca prevenir a ociosidade. O controle dos corpos por meio do invólucro temporal forja uma individualidade orgânica ao utilizar exaustivamente o tempo

em primeiro lugar, através da divisão do tempo e dos segmentos distintos, tais como períodos e práticas de treinamento; em segundo lugar, através da organização desses segmentos em um plano que procede dos mais simples elementos, tais como o posicionamento dos dedos no exercício militar; em terceiro lugar, através da distribuição de um fim a esses segmentos sob a forma de um exame, e, finalmente, através da produção de uma série que atribui exercícios a cada indivíduo de acordo com a classe. $^{12}$

Com o controle do tempo e do espaço e com a combinação de forças entre os corpos, o poder disciplinar produz uma individualidade em que o corpo se sujeita a cumprir uma demanda. Esse processo sobre os corpos não se dá somente pelo uso da separação entre tempo e espaço, mas também pelas técnicas básicas como a observação hierárquica, o julgamento normalizador e o exame.

Com a explosão demográfica do século XVIII, surge o problema do

\footnotetext{
${ }^{11}$ Michel Foucault, Vigiar e punir, 2010, p. 142.

${ }^{12}$ Ibidem, p. 137.
} 
controle sobre o corpo social e, também, sobre o indivíduo. A arquitetura surge com o papel de ordenar as multiplicidades dos indivíduos, promovendo uma observação hierárquica do comportamento individual, tornando os indivíduos visíveis. Dentro de toda vigilância, há também uma hierarquização dos indivíduos que ocupam aquele espaço. Esse olhar não funciona somente de cima para baixo, mas também de forma multidirecional, de modo que todos são afetados pela totalidade dos efeitos desse poder, até mesmo os supervisores de um hospital, por exemplo.

O olhar hierárquico avalia e julga os indivíduos de acordo com a norma, que segundo Foucault, é um padrão de comportamento estabelecido pela sociedade. Qualquer mínimo desvio é punido, estabelecendo assim uma hierarquia entre sujeitos bons e maus. Segundo ele "a norma introduz, como um imperativo útil e como resultado de medição, todos os matizes de diferenças individuais. A norma assim estabelece a figura do normal como princípio de coerção para a figura do anormal"13.

É notório como cada pessoa incorpora e faz valer as normas e regras sociais, punindo qualquer pessoa que saia do padrão estabelecido. A punição da qual Foucault se refere não é a jurídica, exercida pelo direito, mas a coação moral, exercida pelos membros da sociedade. Por medo da crítica ou de não aceitação por parte da sociedade, muitas pessoas acabam por se anular e aderir ao padrão do grupo social ao qual pertencem. Essa forma de coação é social, e por ser indireta, é tão eficaz quanto às exercidas pelas leis, pois a coação social pode ser praticada por qualquer membro da sociedade e a todo momento. Dessa forma, as regras sociais se impõem e se afirmam.

O exame, segundo o autor, é uma forma de efetivação do poder disciplinar, fundindo o olhar hierárquico ao julgamento normalizador. Citando o exemplo da psiquiatria, o exame nessa área produz uma grande quantidade de informação sobre os pacientes por meio de entrevistas, das consultas, e dos interrogatórios.

${ }^{13}$ Ibidem, p. 177. 
Ao deixar para trás uma grande quantidade de documentos, o exame intensifica a objetificação do sujeito, produzindo um saber individual sobre cada um. Um elemento importante nesse processo é a função política da escrita, que constitui o saber que é produzido sobre cada indivíduo, seja nos formulários de uma escola ou nos laudos de uma consulta médica.

Esse saber produzido, que é inerente a toda forma de poder, possibilita a avaliação desse sujeito objetificado, como seu desenvolvimento ou não, como sua conduta adequada à norma ou sua ociosidade. O indivíduo, por meio do exame, é forjado como um caso particular. As escolas, por exemplo, usam as informações coletadas dos alunos não somente para controlar sua conduta, mas para saber da vida dos pais.

Portanto, através do exame há uma função política de registros, por meio dos quais se mantêm informações sobre cada indivíduo tratado como caso particular. São coletadas e registradas informações a respeito de cada indivíduo, como o nome, informações, gostos, notas, perfil e saberes. Por meio de registros desse tipo, foi possível desenvolver um saber sobre os indivíduos nos mais diversos âmbitos da sociedade, como os condenados, os alunos, os internados, os loucos. Essa função política da escrita tornou possível uma descrição, normalização e treinamento do indivíduo por meio de técnicas documentárias.

Como resultado do poder disciplinar que se espalhou pela sociedade, o adestramento dos corpos torna o indivíduo potente para o trabalho, ao mesmo tempo que lhe é retirada a energia para a realização de sua vida política. Desse modo, o homem possui a energia para o trabalho, da qual a economia capitalista necessita, mas se encontra em uma posição de sujeição e alienação no que diz respeito a uma consciência e atividade política. 


\section{Andrew Sayer: as implicações normativas na analítica do poder}

A concepção de poder de Michel Foucault abriu um novo horizonte para a análise da sociedade a partir do estudo das relações de poder. Seus estudos possuem influência e implicação em diversos autores que analisam essa questão, mantendo um diálogo vivo com as mais diversas áreas e com os mais variados escritores, sendo atualizados e ganhando novos contornos a partir de novas interpretações. Em meio a um campo tão vasto de investigação, nos interessa focar na crítica de Andrew Sayer a questão do poder em Foucault.

No artigo intitulado Power, causality and normativity: a critical realist critique of Foucault, Sayer não só atualiza a discussão foucaultiana sobre o poder, como cria novos conceitos a partir desta. Vale primeiro sublinhar que Sayer concorda e avalia de forma cuidadosa a visão microfísica de poder elaborada pelo filósofo francês:

Eu usei Foucault como contraste para partes desta discussão não para rejeitar tudo de suas contribuições para as teorias do poder, mas para destacar algumas das mais relevantes em um embasamento sólido. Seu trabalho é particularmente útil para nos levar além de ideias simplistas de poder como uma coisa ou qualidade separados de objetos concretos e de processos, e pode ser apreendido e mantido, centralizado, verticalizado, ou amplamente processado. ${ }^{14}$

$\mathrm{Na}$ visão do realismo crítico proposta por Sayer, o poder é melhor explicado quando entendido como uma rede de relações que se espalham de forma capilar. Para Sayer, o poder é o potencial, a capacidade de se produzir mudanças, tanto como produção quanto uma capacidade de produzir mudanças. Por isso, para Sayer, o poder pressupõe a noção de causalidade.

Em seu artigo, Sayer defende que para as ciências sociais não há como esquivar-se da tarefa de considerar conceitos éticos densos; por outro lado, a recusa da avaliação normativa não precisa ser entendida como um empecilho na busca da ciência social pela objetividade; a sua ausência é em certo sentido um

\footnotetext{
${ }^{14}$ Andrew Sayer, Power, causality and normativity: a critical realist critique of Foucault, 2012, p. 20, tradução nossa.
} 
empobrecimento nas descrições dos processos sociais. $\mathrm{O}$ autor defende que a recusa comum deriva da crença de que objetividade e valores são incompatíveis.

Na interpretação de Sayer, alguns termos não são apenas descritivos, mas estão impregnados de valores normativos, por exemplo: opressão, racismo, humilhação, entre outros. Essa valoração não é apenas a descrição de um fato, ela exprime o estado do ser. Dessa forma, o florescimento ou o sofrimento, o bemestar ou o mal-estar estão presentes nessa descrição, se fazendo assim importantes para a ciência social.

O poder aparece então como um elemento muito importante ao se considerar os estados dos indivíduos nos processos sociais. Um governo que oferece bolsas de estudo está promovendo aos jovens uma possibilidade de alcançar e desenvolver suas habilidades. Por sua vez, uma atitude racista é excludente e humilhante, sendo prejudicial para quem sofre tal preconceito. Sayer defende que as descrições normativas dos processos sociais são necessárias para o fornecimento de relatos adequados, explicando se o poder pode causar aflição ou sofrimento, por exemplo. Geralmente, as descrições das ciências sociais implicam processos em que o poder causa dominação, sofrimento. Mas o poder também pode ser colocado em termos positivos, como fortalecimento. A consideração do caráter valorativo e normativo do poder defendida pelo autor é inspirada não só no realismo crítico, como também do movimento neoaristotélico.

Para Sayer, Foucault elaborou uma teoria criptograficamente normativa, como já havia indicado Jürgen Habermas:

A historiografia genealógica deve, em atitude rigorosamente descritiva, remontar para trás dos universos discursivos no interior dos quais se discutem apenas normas e valores. Ela coloca entre parênteses as pretensões normativas de validade tanto como as pretensões sobre a verdade proposicional, abstendo-se de perguntar se algumas formações de discurso e de poder poderiam ser mais justificadas que outras. ${ }^{15}$

\footnotetext{
${ }^{15}$ Jürgen Habermas, O discurso filosófico da modernidade, 2000, p. 394.
} 
Em O discurso filosófico da modernidade, de 2000, Habermas critica uma pretensão de neutralidade na genealogia foucaultiana. Para o pensador alemão, Foucault evitou tomar partido, negando o convite esquerdista de abordar o poder como mal, opressor e estéril, mas também não define o poder como algo bom, genuíno, que deve ser exercido. A questão é que a falta de noções normativas, ou a recusa de Foucault em apresentá-las, torna-se um empecilho para explicar questões como por que resistir? Ou: como resistir às disciplinas?

Assim como Habermas, o argumento que Sayer apresenta tenta mostrar como Foucault evitou fazer uma valoração ética em sua analítica do poder, abstendo-se de vincular o poder a termos valorativos e normativos como correto, errado, bom ou ruim. Nem mesmo em A vontade de saber, onde Foucault claramente defende o poder enquanto positivo, há qualquer consideração sobre valoração; diz Sayer:

Assim, embora ele utilmente ressalte que o poder pode tanto criar (e ainda produzir prazer) como também restringir ou destruir, ele se recusa a esclarecer quais instâncias de poder que criam, moldam, limitam ou destroem são boas ou ruins. ${ }^{16}$

Dessa forma, quando Foucault afirma que devemos parar de nos referir ao poder em termos negativos e evidenciar o poder como positivo, ele não está fazendo uma valoração ética, e sim dizendo que o poder é mais positivo do que negativo porque introduz algo na realidade, produzindo discurso, saberes, o próprio indivíduo e o conhecimento que se tem sobre ele.

Ao descrever o modelo disciplinar da sociedade industrial, Foucault não especifica se a normalização e a disciplina causam sofrimento ou florescimento; ou se há um grau bom e necessário de disciplinarização e um grau ruim. Por exemplo, ao mesmo tempo em que a disciplina pode causar a alienação e a formação de corpos dóceis, em uma escola ela pode gerar alunos respeitosos e

\footnotetext{
${ }^{16}$ Andrew Sayer. Power, causality and normativity: a critical realist critique of Foucault, 2012, p. 18, tradução nossa.
} 
compromissados e pode prevenir muitos acidentes no trânsito. Sayer argumenta que se não é dito se esse poder é bom ou ruim, pouco se sabe sobre ele:

\begin{abstract}
Ao se recusar a avaliar, Foucault não apenas gerou seu próprio ativismo político radical - claramente direcionado à redução do sofrimento ininteligível, mas enfraqueceu suas análises de poder. Evitar a questão do que constitui o florescimento e o sofrimento - em outras palavras, evitar uma abordagem crítica - nos impede de descrever e avaliar adequadamente o poder social. ${ }^{17}$
\end{abstract}

A palavra opressão, poucas vezes usada por Foucault, tem a ver com a cautela que o autor tinha ao se referir ao poder como algo negativo. A palavra usada muitas vezes foi dominação, que está vazia de posicionamento valorativo no sentido ético, tendo mais uma função descritiva. Ser dominado por um sistema de hierarquização disciplinar, por exemplo, não é algo desejável, mas algo que possui uma valoração política: é como ter ou não poder, exercer sua liberdade ou estar em uma situação de desvantagem frente às relações de poder na qual está envolvido.

Sayer sustenta que a condição humana não pode ser suficientemente descrita se deixamos de lado as formas particulares que causam bem-estar ou mal-estar nos indivíduos. Para que sejam evitados relatos ambíguos e enigmáticos, a valoração crítica e o julgamento normativo são mais que uma opção, tornam-se uma necessidade para as ciências sociais. Dessa forma, o autor conclui que a descrição foucaultiana de poder é insuficiente e enigmática.

\title{
5. Considerações finais
}

Do exame da analítica do poder depreende-se que a proposta de Foucault é descrever o poder da microestrutura para a macroestrutura, abordando como funcionam as táticas, os mecanismos e os dispositivos de poder. A análise de um

\footnotetext{
${ }^{17}$ Andrew Sayer. Power, causality and normativity: a critical realist critique of Foucault, 2012, p. 20, tradução nossa.
} 
poder centrado na disciplina e no adestramento dos corpos desloca o protagonismo tradicional conferido ao Estado para a pluralidade das forças espalhadas por todo corpo social, que se articulam valendo-se de métodos e procedimentos que são manipuladas por vários agentes. Sendo assim, o Estado é apenas uma das formas terminais das forças microfísicas de poder, mas não a forma unitária de todo o poder.

Mesmo concordando com a noção microfísica de poder, Sayer defende que não há em Foucault uma valoração normativa do poder. A falta de definir o poder em termos éticos, como bom ou ruim, ou quais instâncias de poder que cria e molda os sujeitos são boas ou necessárias, constitui uma falha na descrição foucaultiana do poder.

No entanto, seria necessário chamar atenção para dois pontos importantes: (1) quando Foucault fala do poder disciplinar, em que o corpo está envolvido em uma maquinaria de poderes muito apertados, em momento nenhum o autor usa o termo opressão, pois ao contrário da ingenuidade do poder soberania, a disciplina só exclui o indivíduo em última instância. Desse modo, a dominação ou modelagem dos corpos apresenta uma valoração política, mas não ética; (2) ainda que não tomando partido quanto à valoração e a normatividade do poder e seus efeitos, e no máximo usando termos como positivo e negativo, é necessário esclarecer que o fato de Foucault ter evitado uma valoração normativa não tira o peso crítico de sua obra, que na maioria das vezes é lida sob a ótica de um julgamento valorativo: seja por ingenuidade, costume de considerar o poder como negativo, seja porque, como defende Sayer, Foucault de fato e ao cabo não conseguiu evitar a imparcialidade crítica. 


\section{Referências}

ALLEN, Amy. The anti-subjective hypothesis: Michel Foucault and the death of the subject. The Philosophical Forum, v. 16, n. 2. 2000. p. 113 -130. Disponível em: https://doi.org/10.1111/0031-806X.00031. Acesso em 25 jul. 2019.

DREYFUS, Hubert L.; RABINOW, Paul. Michel Foucault: uma trajetória filosófica. Para além do estruturalismo e da hermenêutica. Rio de Janeiro: Forense Universitária, 1995.

FOUCAULT, Michel. História da Sexualidade: A Vontade de Saber. 19. ed. São Paulo: Graal, 2009.

FOUCAULT, Michel. Vigiar e Punir: nascimento da prisão. 38. ed. Petrópolis: Vozes, 2010.

HABERMAS, Jürgen. O discurso filosófico da modernidade. São Paulo: Martins Fontes, 2000.

MACHADO, Roberto. Por uma genealogia do poder. In: FOUCAULT, Michel. Microfísica do poder. 25. ed. Rio de Janeiro: Graal, 2012.

SAYER, Andrew. Power, causality and normativity: a critical realist critique of Foucault. Disponível em:

https://www.tandfonline.com/doi/abs/10.1080/2158379X.2012.698898. Acesso em: 23 jun. 2019.

TAYLOR, Dianna. Michel Foucault: conceitos fundamentais. Rio de Janeiro: Vozes, 2018.

\section{Referência para citação deste artigo}

DE BARROS, Igor. A concepção relacional do poder em Foucault e a omissão da valoração ética. Revista PHILIA |Filosofia, Literatura \& Arte, Porto Alegre, volume 1, número 2, p. 319 - 339, outubro de 2019. 